\title{
Effectiveness of a web-based physical activity intervention for adults with Type 2 diabetes-A randomised controlled trial ${ }^{\llcorner}$
}

\author{
Cally A. Jennings a,b,*, Corneel Vandelanotte ${ }^{\text {a }}$, Cristina M. Caperchione ${ }^{c}$, W. Kerry Mummery ${ }^{\text {b }}$ \\ a CQUniversity Australia, Institute for Health and Social Science Research, Centre for Physical Activity Studies, Rockhampton, Queensland, Australia \\ ${ }^{\mathrm{b}}$ Faculty of Physical Education and Recreation, University of Alberta, Edmonton, Alberta, Canada \\ c Faculty of Health and Social Development, University of British Columbia, Kelowna, British Columbia, Canada
}

\section{A R T I C L E I N F O}

Available online 15 December 2013

\section{Keywords:}

Web-based

Internet

Physical activity

Type 2 diabetes

Intervention

Randomised controlled trial

\begin{abstract}
A B S T R A C T
Objective. This study examined the effectiveness of a fully automated web-based programme to increase physical activity in adults with Type 2 diabetes.

Methods. Between May and July 2010, participants were randomly allocated into either a 12-week intervention $(n=195)$ or a control $(n=202)$ group. Participants were adults diagnosed with Type 2 diabetes, residing in Australia. Participants were assessed at baseline, 12 and 36 weeks. The primary physical activity outcome was self-reported minutes of total physical activity. Secondary physical activity outcomes included minutes spent walking, and engaged in moderate, and vigorous physical activity. Additional measures included website satisfaction and website usage. The intervention consisted of a 12-week web-based physical activity intervention developed based on the Theory of Planned Behavior and self-management framework. Data were analysed from 2011 to 2012 .

Results. There was a significant group-by-time interaction $\left(X^{2}(d f=1)=6.37, p<.05\right)$ for total physical activity favouring the intervention group $d=0.11$, for those who completed the intervention, however this was not significant in the intention-to-treat analysis $d=0.01$. The intervention yielded high website satisfaction and usage.

Conclusions. In general, there is some evidence for the effectiveness of web-based interventions for improving physical activity levels; however it is clear that maintaining improvements remains an issue.
\end{abstract}

(c) 2013 Elsevier Inc. All rights reserved.

\section{Introduction}

Physical inactivity is a major public health concern. High levels of physical inactivity are related to an increase in the rate of chronic diseases, including cardiovascular disease, some forms of cancer and Type 2 diabetes (World Health Organization, 2004). Individuals diagnosed with Type 2 diabetes frequently have lower physical activity levels than the general population (Hays and Clark, 1999; Morrato et al., 2007) and increasing their physical activity significantly improves quality of life and reduces or delays the onset of physiological complications such as, reduced life expectancy, microvascular damage and macrovascular complications and significantly diminished quality of life or even morbidity (Healy et al., 2008; World Health Organization, 1999).

Traditionally, individuals diagnosed with Type 2 diabetes would undergo face-to-face education to encourage behaviour change in

\footnotetext{
The study is registered with the Australian New Zealand Clinical Trials Registry (ACTRN12612000730808).

* Corresponding author at: Van Vliet Centre, Faculty of Physical Education and Recreation, University of Alberta, Edmonton, Alberta T6G 2H9, Canada.

E-mail address: cally1@ualberta.ca (C.A. Jennings).
}

areas such as physical activity in order to self-manage their condition (American Diabetes Association, 2006). Face-to-face interventions have previously proven successful for improving physical activity (Conn et al., 2011). Face-to-face education is resource and cost intensive and is often limited by geography (Marshall et al., 2004). An alternative is web-based delivery. Web-based interventions have demonstrated positive changes in short-term physical activity, however less evidence exists to support the long-term physical activity maintenance (Davies et al., 2012; Vandelanotte et al., 2007). Web-based physical activity programmes offer advantages such as being able to deliver interactive and individualised interventions to large groups (McKay et al., 2001; Vandelanotte et al., 2007). Examples of interactive features can include goal setting, updated content, instantaneous feedback, self-monitoring, chat rooms, and computer-tailoring. Web-based delivery also overcomes geographic barriers and offers the convenience of on-demand, $24 \mathrm{~h}$ a day accessibility (Glasgow et al., 2003).

The last decade has seen an increasing number of web-based physical activity interventions (Davies et al., 2012; Norman et al., 2007; Vandelanotte et al., 2007), however, few web-based interventions have been designed for Type 2 diabetes and most of those are mainly focused on nutrition (Armstrong and Powell, 2008; Armstrong et al., 2007; Glasgow et al., 2003; McKay et al., 2002). Furthermore, 
some that have taken physical activity into account do not specifically implement behavioural strategies aimed to target change in physical activity (Glasgow et al., 2003; McKay et al., 2002) or do not include physical activity as an outcome measure (Nes et al., 2012). Only a few web-based interventions have been designed to specifically elicit changes in physical activity (Glasgow et al., 2010; Kim and Kang, 2006; Liebreich et al., 2009; Lorig et al., 2010; Richardson et al., 2007).Therefore, the primary purpose of this study was to evaluate the long-term effectiveness of a 12-week theory and web-based programme, designed specifically for individuals diagnosed with Type 2 diabetes to increase physical activity. We hypothesised that, compared with the control group participants in the web-based intervention group would exhibit greater improvements in physical activity. The secondary purpose was to evaluate participant's satisfaction and usage of a web-based physical activity intervention.

\section{Methods}

\section{Participant recruitment and eligibility}

Participants were invited to take part in the randomised controlled trial through an email invitation $(n=12,923)$ distributed by the Queensland Branch of Diabetes Australia. The email contained an invitation to participate, contact details and an information sheet. Interested participants were directed to either call or email the project manager located at CQUniversity in Rockhampton, Queensland. All participants who expressed interest were contacted via telephone and screened for eligibility criteria, which included; a) diagnosed with Type 2 diabetes; b) available access to internet and email; c) the ability to read and understand English; d) above 18 years old; e) a "no" response to all questions on the physical activity readiness questionnaire (PAR-Q) (a "yes" response to one or more questions required physician approval prior to participating in the study) (Thomas et al., 1992); f) currently not receiving diabetes education and g) not meeting the national physical activity guidelines ( $\geq 150$ min moderate physical activity per week). Rolling recruitment took place between 26 May and 19July 2010. Ethical approval was obtained from CQUniversity's Human Research Ethics Committee (HREC) and the study is registered with the Australian New Zealand Clinical Trials Registry (ACTRN12612000730808).

\section{Procedure and randomisation}

A minimum sample size of 220 was chosen for the study representing $80 \%$ power at a $\leq 0.05$ significance level to detect a medium effect size or greater (Cohen, 1992). Due to the length of the follow-up period the sample size was inflated for drop-out as previous studies have reported as high as 70\% attrition for a six-month follow-up period (Kosma et al., 2005). Eligible participants were assigned to either the control or intervention group through a single sequence of computer-generated numbers that randomly allocated participants based on their call number from initial screening. To ensure concealment, the lead researcher conducting randomisation was blinded from participant's group allocation until baseline screening of the participant had been completed. Following baseline telephone screening participants were sent a welcome email, containing a link to the programme website ('Diabetes in Check') and their personal login details. Upon first login to the website participants were required to provide informed consent and complete the baseline questionnaire before they could access the website. Participants were not aware of their group allocation until they had completed the baseline questionnaire. Both groups received access to the 'Diabetes in Check' website, however participants in the control group were restricted to accessing a modified version of the website that limited the information that they could access. At the completion of the 12-week intervention phase, the website remained accessible; however, no further updates were made to the website. All participants (control and intervention groups) were mailed a YAMAX Digi-walker SW-9700 pedometer to use as a motivational and self-monitoring tool during the intervention and participants were able to retain the pedometers upon completion of the intervention period. Pedometers were provided to both groups to ensure that any effects on physical activity from the pedometer were accounted for. YAMAX Digi-walker SW-9700 pedometers were chosen due to their accuracy, reliability (Schneider et al., 2003) and validity (Crouter et al., 2003).

Assessments were collected online via the 'Diabetes in Check' website at baseline, immediately post-intervention (12 weeks) and 6 months following completion of the intervention ( 36 weeks from baseline). For the 12 and 36week assessments the subsequent procedure was followed. Participants were first sent an email notifying them that their web-based questionnaire was due for completion. The email was personally addressed and contained information about and a link to the questionnaire. E-mail reminders were sent at 5, 10 and 15 days to enhance survey completion. Upon completion, participants were sent a personally addressed email thanking them for their participation.

\section{Intervention website}

The programme utilises a self-management approach and was developed based on the Theory of Planned Behavior (Ajzen, 1991). The self-management approach aims to encourage the development of skills and abilities to initiate and maintain health-related behaviour change (American Diabetes Association, 2006). Previous studies have demonstrated the effectiveness of the TPB variables in explaining physical activity behaviour and for using the TPB as a framework for developing physical activity interventions (Bauman et al., 2002; Blanchard et al., 2002; Davies et al., 2010; Hagger et al., 2002). For example, Bauman et al. (2002) reported that $67 \%$ of the variables within the TPB are consistently supported throughout physical activity studies. Additionally, the TPB has been shown to be effective in producing behaviour change in chronic diseased populations (Courneya and Friedenreich, 1999; Jones et al., 2007; Vallance et al., 2008). To operationalise TPB constructs (attitude, perceived behavioural control and subjective norm) and self-management the following components were implemented: educational modules, social support, positive reinforcement, personalised feedback and a number of activities such as goal setting and planning. The website encompassed seven main sections; 'home', 'online logbooks', 'workbook', 'library', 'goals', ‘discussions' and 'contacts' (Table 1). Weekly education modules in the workbook section included a new module topic each week that operationalised TPB constructs

Table 1

Overview of Diabetes in Check website components.

\begin{tabular}{|c|c|}
\hline Section & Overview \\
\hline Home & $\begin{array}{l}\text { The landing page for the website, presenting personalised } \\
\text { information, quick overview of progress to date in relation to the } \\
\text { online logbooks and workbook and links to any other section of } \\
\text { the website (Appendix B). }\end{array}$ \\
\hline Online logbooks & $\begin{array}{l}\text { Intervention participants were able to complete online logbooks } \\
\text { for physical activity, blood glucose, blood pressure daily, and } \\
\text { weekly body weight (Appendix C). The online logbooks offer a } \\
\text { numerical and graphical representation of entry history. }\end{array}$ \\
\hline Workbook & $\begin{array}{l}\text { Education material was provided to build upon self-management } \\
\text { knowledge and diabetes education. To encourage return visits } \\
\text { and continued usage the educational modules were sequentially } \\
\text { delivered (Steele et al., 2007b). The education modules were split } \\
\text { into one 'Listen', 'Read' and 'Do' for each week (Appendix D). } \\
\text { Educational material and content were developed consistent } \\
\text { with diabetes education guidelines and in conjunction and col- } \\
\text { laboration with diabetes educators. }\end{array}$ \\
\hline Library & $\begin{array}{l}\text { The library section contained a collection of articles pertinent to } \\
\text { individuals diagnosed with Type II diabetes, as well as informa- } \\
\text { tion regarding the use of the website. Articles addressed topics } \\
\text { such as: just being diagnosed, living with diabetes, eating well, } \\
\text { diabetes and medications and understanding diabetes. Articles } \\
\text { were provided by the Queensland branch of Diabetes Australia, } \\
\text { for use for the programme's duration. }\end{array}$ \\
\hline Goals & $\begin{array}{l}\text { Participants were able to set weekly physical activity goals and } \\
\text { receive personalised feedback based on meeting their pre- } \\
\text { defined goals for each of } 12 \text { weeks (Appendix E). The automated } \\
\text { and personalised physical activity messages were designed to be } \\
\text { perceived as personally relevant and encourage continued use of } \\
\text { the logbooks (Brug et al., 1999). }\end{array}$ \\
\hline Discussion & $\begin{array}{l}\text { Asynchronous communication was facilitated through a } \\
\text { discussion board, where participants were encouraged to join } \\
\text { discussions with the programme manager and other } \\
\text { participants. Social support through discussion forums has } \\
\text { previously been shown to be a highly used and valuable website } \\
\text { resource if implemented and effectively moderated to facilitate } \\
\text { supportive exchanges (Rotondi et al., 2005). }\end{array}$ \\
\hline Contacts & $\begin{array}{l}\text { The 'contacts' section enabled participants to upload and store } \\
\text { personal information and contact information for their diabetes } \\
\text { support team, send questions, and access links to Diabetes } \\
\text { Australia and additional diabetes related websites. }\end{array}$ \\
\hline
\end{tabular}


and self-management (Steele et al., 2007a), which are outlined in Appendix A. In addition to the website, participants in the intervention group were also distributed a weekly email reminder, the content of which changed weekly, but always contained a link to the intervention website. Examples of various screen-shots from the website are provided in Appendices B-E.

\section{Control group}

The control group had access to a modified version of the website that restricted the information that they could access. As such the control group could only view a modified 'home', and 'contacts' section of the website. The home page only displayed a static message that thanked participants for completing the questionnaires and directed them to the 'contacts' section on the modified website. The 'contacts' section was identical to that of the intervention group. Aside from being provided pedometers and emailed to complete the 12 and 36-week questionnaires, no further contact or intervention was provided to the control group throughout the intervention.

\section{Measures}

Demographic data and physical activity behaviour were obtained for the intervention and control groups at baseline, 12 and 36 weeks. For the intervention group, an additional questionnaire assessing programme satisfaction was included immediately post-intervention (12 weeks).

Demographic characteristics included; age, gender, ethnicity, height $(\mathrm{cm})$, weight (kg), marital status, education, employment status, income, time since diagnosis and medication status. Height and weight were obtained in order to calculate participants' body mass index (BMI). BMI was calculated by dividing weight $(\mathrm{kg})$ by height $\left(\mathrm{m}^{2}\right)$. Items were based on the Australian Bureau of Statistics (Australian Bureau of Statistics, 2006) and Australian Institute of Health and Welfare (Australian Institute of Health and Welfare, 2008). Physical activity was measured using the long form International Physical Activity Questionnaire (IPAQ). The IPAQ has been shown to be a valid and reliable instrument to measure physical activity among adults at a population level (Craig et al., 2003) and has previously shown to be sensitive enough to detect behaviour change in intervention research (Spittaels et al., 2007a,b). The IPAQ assesses the frequency (days) and duration ( $\mathrm{min}$ ) of physical activity during the previous 7 days. For the purposes of the current study the primary outcome derived from the IPAQ was, total minutes of physical activity per week (cumulative total for walking, moderate and vigorous activity). Additionally, secondary physical activity outcomes including; minutes per week spent walking and engaged in moderate, and vigorous intensity activity were calculated along with total minutes spent sitting on weekdays, and weekends.

Programme satisfaction was measured for participants in the intervention group to examine overall website satisfaction and usefulness of various programme features. The survey was adapted from the Health-eSteps (Steele et al., 2007a) and Diabetes NetPLAY (Liebreich et al., 2009) programmes. The questionnaire contained 17 items measured using a 5 point Likert scale that ranges from 'strongly agree' to 'strongly disagree' in addition to three open ended questions for participants to record likes/dislikes and recommendations. Additionally, website usage statistics were automatically collected for all study participants, using a unique identification number.

\section{Statistical analysis}

Descriptive statistics of demographic characteristics and baseline data for physical activity were calculated and compared to detect differences between groups at baseline and to conduct drop-out analysis using a series of independent sample $t$-tests and chi-square analysis. To examine if there was a significant effect on outcomes generalised estimating equation (GEE) models were applied to test for time (baseline, 12 weeks and 36 weeks), group (intervention and control) and interaction (group by time) effects for non-normally distributed data (physical activity). Separate models for all primary and secondary physical activity outcome variables were tested. Models were specified using an unstructured working correlation matrix. Age, gender, ethnicity, marital status, education, employment income and BMI were covariates in all analyses. Both intention-to-treat (ITT) and completer's analyses were undertaken using GEE. ITT analysis included all participants using baseline carried forward values for missing data at 12 and 36 weeks. Completer's analysis only included participants' data that completed all three assessment periods. Additionally, effect sizes $(d)$ were computed to represent the impact of the web-based programme on the primary outcome variable total minutes of physical activity per-week at
12 and 36 weeks for both ITT and completer's analyses. Descriptive statistics for website satisfaction and usefulness measures were calculated as percentages of participants that rated website features favourably by combining 'strongly agree' and 'agree' compared to combined 'neutral', 'disagree', and 'strongly disagree'. Difference in mean number of logins (as indicator of website usage) between groups was analysed using an independent sample $t$-test and descriptive statistics for usage of the various website components are provided. All analyses were undertaken using SPSS Version 19.0, with the significance level being set to $p<.05$.

\section{Results}

A total of 568 individuals contacted the project manager and were screened for eligibility criteria by phone. As a result 436 individuals were deemed eligible to participate. A total of 397 individuals completed the baseline questionnaire and were randomised, resulting in 202 participants in the control and 195 participants in the intervention group (Fig. 1). At 12 weeks, 71\% $(n=144)$ of the control group participants and $61 \%(n=118)$ of the intervention group participants completed the post-intervention questionnaire (total of $66 \%)$. At 36 weeks, $49 \%(n=99)$ of the control group and $45 \%$ ( $n=87$ ) of the intervention group completed the follow-up questionnaire (total of $47 \%$ ). Complete data for the three assessment periods were obtained for $46 \%(n=92)$ of the participants in the control and $42 \%(n=82)$ of the participants in the intervention group. Drop-out analysis revealed no significant differences for gender, age, BMI, ethnicity, educational attainment, employment status, and income or baseline level of physical activity at 12 and 36 weeks. The only significant difference $\left(X^{2}(d f=1)=5.13, p<.05\right)$ was for 'group' (intervention or control), only at the 12 -week time point, with a greater proportion of the control group completing the postintervention questionnaire. Additional drop-out analysis was conducted for website usage, results demonstrated that drop-out was higher for those who had lower usage overall $(t(202)=4.92$, $p<.001)$ and for those in the intervention group who had lower recorded website usage $(t(95)=5.48, p<.001)$.

At baseline the mean age of participants was $58 \pm 10.30$ years, the average length of diagnosis was $8.35 \pm 6.72$ years and average BMI for the sample was $34.76 \pm 17.40 \mathrm{~kg} / \mathrm{m}^{2}$. Further descriptive information is provided in Table 2 . There were no significant differences for any of the baseline measures between the intervention and control groups at baseline.

\section{Effect on physical activity}

ITT analysis (Table 3) demonstrated significant time effects for all physical activity measures. There were no group by time interactions. Effect sizes for total minutes of physical activity per-week were $d=0.06$ and $d=0.01$ at 12 and 36 weeks, respectively. The completer's GEE analysis showed that there was a significant time effect for all physical activity measures (see Table 4). There were significant group by time interactions for total physical activity $\left(X^{2}\right.$ $(d f=1)=6.37, p<.05)$ and weekday sitting time $\left(X^{2}(d f=1)=\right.$ 7.16, $p<.05)$, whereby the intervention group significantly increased total physical activity in comparison to the control group. Effect sizes for total minutes of physical activity per-week were $d=0.27$ and $d=0.11$ at 12 and 36 weeks, respectively. Additionally, the intervention group significantly reduced weekday sitting in comparison to the control group.

\section{Intervention satisfaction}

Overall the intervention website was rated favourably (either 'Agree' or 'Strongly Agree'): the majority of participants rated the website as user friendly (91\%), liked the overall presentation of the website (91\%), were able to easily navigate the website (92\%), 


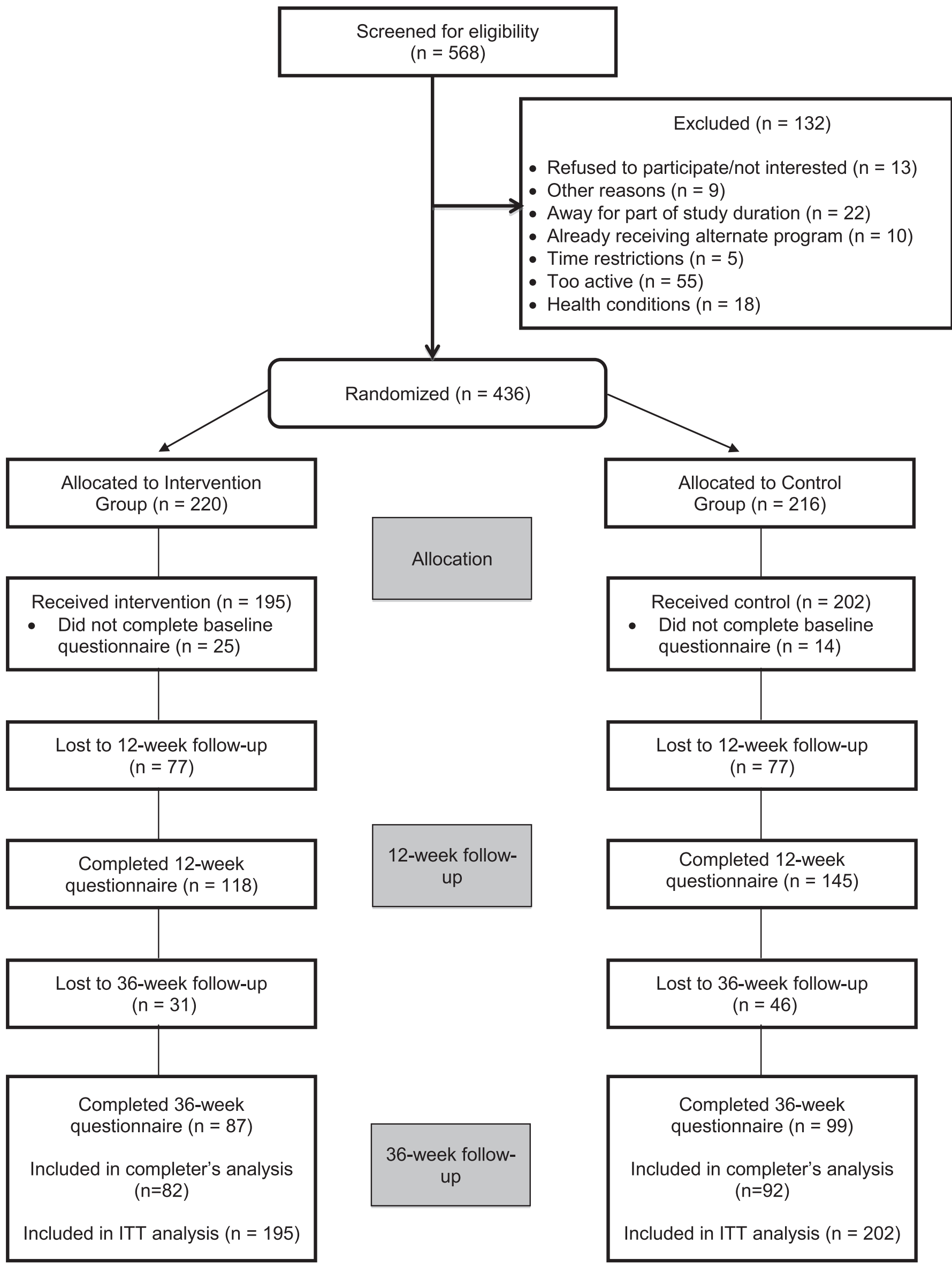


Table 2

Baseline demographic characteristics. Australia 2010-2011.

\begin{tabular}{|c|c|c|c|c|}
\hline \multirow[t]{3}{*}{ Variable } & \multicolumn{3}{|l|}{ Group } & \multirow[t]{3}{*}{$p$-Value } \\
\hline & \multirow{2}{*}{$\frac{\text { Overall }(n=397)}{n(\%)}$} & \multirow{2}{*}{$\frac{\text { Control }(n=202)}{n(\%)}$} & \multirow{2}{*}{$\frac{\text { Intervention }(n=195)}{n(\%)}$} & \\
\hline & & & & \\
\hline Gender & & & & .8 \\
\hline Male & $208(52.4)$ & $107(53)$ & $101(51.8)$ & \\
\hline Female & $189(47.6)$ & $95(47)$ & $94(48.2)$ & \\
\hline Marital status & & & & .7 \\
\hline Never married & $29(7.3)$ & $15(7.4)$ & $14(7.2)$ & \\
\hline Widowed & $22(5.5)$ & $13(6.4)$ & $9(4.6)$ & \\
\hline Divorced and or separated & $53(13.4)$ & $27(13.4)$ & $26(13.3)$ & \\
\hline Married & $293(73.8)$ & $147(72.8)$ & $146(74.9)$ & \\
\hline Education & & & & .1 \\
\hline High school or less & $150(37.8)$ & $78(38.6)$ & $72(36.9)$ & \\
\hline More than high school & $247(62.2)$ & $124(61.4)$ & $123(63.1)$ & \\
\hline Employment status & & & & .3 \\
\hline Employed & $215(54.2)$ & $112(55.5)$ & $103(52.8)$ & \\
\hline Retired & $117(29.5)$ & $58(28.7)$ & $59(30.3)$ & \\
\hline Unemployed & $65(16.3)$ & $32(15.8)$ & $33(16.9)$ & \\
\hline Income & & & & 6 \\
\hline Less than $\$ 34,999$ & $137(34.5)$ & $70(34.7)$ & $67(34.4)$ & \\
\hline$\$ 35,000$ to $\$ 74,999$ & $117(29.5)$ & $57(28.2)$ & $60(30.8)$ & \\
\hline$\$ 75,000$ or more & $120(30.2)$ & $64(31.7)$ & $56(28.7)$ & \\
\hline Do not know/not sure & $23(5.8)$ & $11(5.4)$ & $12(6.2)$ & \\
\hline Blood glucose medication & & & & .2 \\
\hline Yes & $321(80.9)$ & $168(83.2)$ & $153(78.5)$ & \\
\hline No & $76(19.1)$ & $34(16.8)$ & $42(21.5)$ & \\
\hline Other medications & & & & .1 \\
\hline Yes & $310(78.1)$ & $166(82.2)$ & $144(73.8)$ & \\
\hline \multirow[t]{2}{*}{ No } & $87(21.9)$ & $36(17.8)$ & $51(26.2)$ & \\
\hline & Mean (SD) & Mean (SD) & Mean (SD) & \\
\hline Age (years) ${ }^{\mathrm{b}}$ & $58.2(10.3)$ & $58.29(9.9)$ & $58.21(10.6)$ & .9 \\
\hline $\mathrm{BMI}\left(\mathrm{kg} / \mathrm{m}^{2}\right)^{\mathrm{b}}$ & $33.5(6.6)$ & $33.55(6.4)$ & $33.45(6.7)$ & .9 \\
\hline Total physical activity $(\mathrm{min} / \text { week })^{\mathrm{c}}$ & $517(195.5-1012.5)$ & $480(180-994)$ & $540(221-1020)$ & .8 \\
\hline
\end{tabular}

${ }^{a}$ Difference between groups at baseline measures by $t$-test or chi-square (two-tailed) analysis.

b Data presented as mean (SD).

c Data presented as median (25\%-75\%).

found the information easy to understand (95\%), credible (95\%), and useful (92\%). Participants also found the speed of the website acceptable (84\%). Additionally, $88 \%$ liked being able to access a personalised site and $83 \%$ thought that the information on the website was personally relevant. In regard to specific website components, participants rated the logbooks most favourably (86\%), followed by weekly workbook modules (83\%), weekly email reminders (75\%), goal setting (69\%), weekly goal feedback (61\%), and finally the discussion board (39\%) which rated least favourably.

\section{Website usage}

The average number of logins for both groups was 11.98 for the entire duration of the intervention; the intervention group (21.07 \pm 33.65$)$ recorded significantly greater website logins $(t(195.72)=7.39, p<.001)$ in comparison to the control group ( $3.22 \pm 2.28)$. Additionally, among the participants included in the completer's analysis website logins in the intervention group increased to an average of $37 \pm 44$ logins. The next part of this section reports on website usage for the intervention group only. Within the online logbook section 161 (83\%) participants logged at least one physical activity entry (50.55 \pm 36.64$), 142(72 \%)$ logged at least one blood glucose entry (42.63 \pm 35.69$)$, and 99 (51\%) logged at least one blood pressure entry (26.42 \pm 32.93$)$. Additionally, 141 (72\%) participants recorded at least one weekly weight entry $(6.94 \pm 5.04)$. In the workbook section $162(83 \%)$ participants viewed the workbook at least once, with an average of $28 \pm 13.5$ workbook views. For the library section 190 (97\%) participants viewed the library section at least once with an average of $9.24 \pm 7.71$ views. For the weekly physical activity goals, 126 (65\%) participants set at least one weekly physical activity goal, with an average of $4.6 \pm 3.7$ weekly goals set.
Finally, 51 (26\%) participants wrote at least one discussion post resulting in an accumulation of 173 discussion posts and 2961 views of those discussion posts during the intervention period.

\section{Discussion}

The primary aim of the current study was to determine the longterm effectiveness of a web-based programme designed specifically for individuals diagnosed with Type 2 diabetes to increase physical activity. The findings indicate that although there were substantial increases in physical activity at the completion of the intervention, maintaining these increases six months following the completion of the intervention was problematic. Greater support for maintaining physical activity levels was found in the completer's analysis compared to the ITT analysis, which is likely due to the large drop-out making the ITT too conservative (Eysenbach, 2005).

The intervention resulted in an increase in total physical activity by an average of $265 \mathrm{~min} /$ week per person immediately at the end of the intervention $(d=0.06)$. The observation that the control group also increased physical activity levels could be attributed to the use of pedometers which have previously been shown to act as a motivational tool (Rooney et al., 2003). With respect to the intervention group findings, similar increases in total physical activity have been found in previous web-based studies (Vandelanotte et al., 2007). For example, Winett et al. (2007) found a significant increase in steps per day at seven (1500 steps per day) and eighteen (1000 steps per day) months for the intervention group in comparison to the control group. Winett et al. (2007) provided the intervention group with a 'Guide to Health' programme that included sequentially released education modules, self-monitoring features, goal setting and feedback. Specifically within 
Table 3

Observed estimated marginalised means, standard errors (SE) and differences in physical activity behaviour at baseline, 12 and 36 weeks (ITT analysis). Australia $2010-2011$.

\begin{tabular}{|c|c|c|c|c|c|c|c|}
\hline \multirow[t]{2}{*}{ Outcome $e^{a}$} & \multirow[t]{2}{*}{ Time point ${ }^{\mathrm{b}}$} & \multicolumn{3}{|l|}{ Mean $(\mathrm{SE})^{\mathrm{c}}$} & \multicolumn{3}{|c|}{ Chi square } \\
\hline & & Baseline & 12 weeks & 36 weeks & Time & Group & Group $\times$ Time \\
\hline \multirow[t]{3}{*}{ Total PA } & & & & & $34.2^{* * *}$ & 1.1 & 4.7 \\
\hline & Control & $622.2(140.9)$ & $738.2(167.2)$ & $720.9(168.4)$ & & & \\
\hline & Intervention & $641.5(152.2)$ & $906.7(215.4)^{* *}$ & 745.5 (177.7) & & & \\
\hline \multirow[t]{3}{*}{ Walking } & & & & & $10.6^{* *}$ & 2.3 & 3.4 \\
\hline & Control & $229.1(54.2)$ & $237.7(55.5)$ & $214.1(50.2)$ & & & \\
\hline & Intervention & $251.2(62.6)$ & $319.9(76.4)$ & $236.6(58.3)$ & & & \\
\hline \multirow[t]{3}{*}{ Moderate intensity } & & & & & $45.5^{* * *}$ & 0.5 & 3.1 \\
\hline & Control & 316.9 (79.4) & $405.1(101.4)$ & $417.7(107.3)$ & & & \\
\hline & Intervention & 321.9 (82.9) & $487.7(129.1)$ & $426.4(111.3)$ & & & \\
\hline \multirow[t]{3}{*}{ Vigorous intensity } & & & & & $19.4^{* * *}$ & 0.0 & 3.0 \\
\hline & Control & $51.6(23.6)$ & $79.9(35.8)$ & $73.4(33.6)$ & & & \\
\hline & Intervention & $36.5(16.5)$ & $103.5(53.9)$ & $74.8(34.9)$ & & & \\
\hline \multirow[t]{3}{*}{ Weekday sitting } & & & & & $23.0^{* * *}$ & 2.4 & 4.3 \\
\hline & Control & $390.9(34.4)$ & 370.1 (34.9) & 373.9 (33.6) & & & \\
\hline & Intervention & $438.2(39.0)$ & $375.7(33.9)^{\text {**** }}$ & 406.7 (37.5) & & & \\
\hline \multirow[t]{3}{*}{ Weekend sitting } & & & & & $57.0^{* * *}$ & 2.4 & 4.4 \\
\hline & Control & $288.2(29.3)$ & $257.1(26.6)^{* *}$ & $254.5(25.8)^{* * *}$ & & & \\
\hline & Intervention & 313.8 (31.9) & $262.9(27.0)^{* * * *}$ & $287.45(29.6)^{*}$ & & & \\
\hline
\end{tabular}

Note: Based on GEE analysis results comparing long-term control and intervention group effects from baseline, 12 and 36 weeks.

Note: PA, physical activity.

$* p<.05$.

$* * \quad p<.01$

$* * * \quad p<.001$.

a Physical activity outcomes are presented in min/week.

b Intention-to-treat analysis included 202 participants in the control and 195 in the intervention groups.

c Significance displayed for means indicates significant difference from baseline for group.

the Type 2 diabetes population, Kim and Kang (2006) also reported significant increases in physical activity levels for their web-based intervention group in comparison to a usual care group. The intervention group received a website equipped with interactive features, personalised goal setting, activity planning and personalised information (Kim and Kang, 2006). Additionally, another intervention targeting individuals with Type 2 diabetes found the intervention group significantly increased moderate and vigorous physical activity in comparison to the control group (Liebreich et al., 2009). This research is supported by a recent systematic review which provided support for technology based interventions to promote physical activity in individuals with Type 2 diabetes (Connelly et al., 2013).

Six months following the completion of the 'Diabetes in Check' intervention the increase in physical activity from baseline was reduced to $103 \mathrm{~min} /$ week. This finding is also similar to previous studies that have reported problems in maintaining increases in physical activity over time and highlights the continued need to determine effective strategies to maintain physical activity (Carr et al., 2013; Davies et al., 2012; Glasgow et al., 2003, 2012; Vandelanotte et al., 2007). Maintaining this increase from baseline may offer some clinically

Table 4

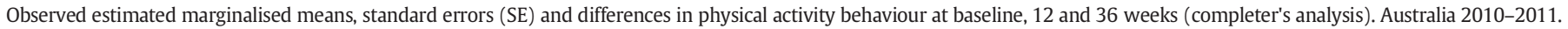

\begin{tabular}{|c|c|c|c|c|c|c|c|}
\hline \multirow[t]{2}{*}{ Outcome $^{a}$} & \multirow[t]{2}{*}{ Time point ${ }^{\mathrm{b}}$} & \multicolumn{3}{|l|}{ Mean $(S E)^{c}$} & \multicolumn{3}{|c|}{ Chi square } \\
\hline & & Baseline & 12 weeks & 36 weeks & Time & Group & Group $\times$ Time \\
\hline \multirow[t]{3}{*}{ Total PA } & & & & & $14.8^{* *}$ & $5.8^{*}$ & $6.4^{*}$ \\
\hline & Control & $644.4(120.0)$ & $727.2(127.3)$ & $843.5(154.7)$ & & & \\
\hline & Intervention & 757.9 (126.5) & $1128.5(189.6)^{* *}$ & $962.1(165.0)$ & & & \\
\hline \multirow[t]{3}{*}{ Walking } & & & & & $10.2^{* *}$ & $6.3^{*}$ & 5.5 \\
\hline & Control & $274.7(67.5)$ & $274.5(50.5)$ & $249.5(52.1)$ & & & \\
\hline & Intervention & $349.0(69.3)$ & $477.7(86.1)$ & $296.7(54.1)$ & & & \\
\hline \multirow[t]{3}{*}{ Moderate intensity } & & & & & $31.5^{* * *}$ & 2.5 & 4.6 \\
\hline & Control & $267.8(54.5)$ & $320.6(68.8)$ & $435.4(92.3)^{*}$ & & & \\
\hline & Intervention & $294.8(56.0)$ & $484.3(95.0)^{*}$ & $489.3(99.6)$ & & & \\
\hline \multirow[t]{3}{*}{ Vigorous intensity } & & & & & $14.1^{* *}$ & 0.1 & 1.2 \\
\hline & Control & $42.6(23.8)$ & $62.0(26.5)$ & $87.4(37.3)$ & & & \\
\hline & Intervention & $33.6(13.7)$ & $90.0(37.1)$ & $94.1(39.1)$ & & & \\
\hline \multirow[t]{3}{*}{ Weekday sitting } & & & & & $19.8^{* * *}$ & 0.6 & $7.2^{*}$ \\
\hline & Control & $403.1(47.6)$ & $377.4(50.7)$ & $371.3(46.6)$ & & & \\
\hline & Intervention & $428.0(41.8)$ & $317.1(32.4)^{* * *}$ & $358.0(39.0)$ & & & \\
\hline \multirow[t]{3}{*}{ Weekend sitting } & & & & & $51.4^{* * *}$ & 0.2 & 2.6 \\
\hline & Control & $364.7(46.5)$ & $295.3(39.5)^{* *}$ & $290.0(38.8)^{* *}$ & & & \\
\hline & Intervention & 363.5 (37.9) & $263.2(26.5)^{* * *}$ & $296.3(30.5)^{*}$ & & & \\
\hline
\end{tabular}

Note: Based on GEE analysis results comparing long-term control and intervention group effects from baseline, 12 and 36 weeks.

Note: PA, physical activity.

$* p<.05$.

$* * \quad p<.01$.

$* * * \quad p<.001$.

a Physical activity outcomes are presented in min/week

b Completer's analysis included 91 participants in the control and 81 in the intervention groups.

c Significance displayed indicates significant difference from baseline for group. 
significant improvements for the management of the long-term management of their Type 2 diabetes. As research indicates a minimum of $150 \mathrm{~min} /$ week of moderate activity can result in improvements for glycaemic control, weight maintenance and reductions in cardiovascular disease risk (Sigal et al., 2006). The present study adds to the current literature due to the unique combination of intervention features including sequentially released education modules, physical activity goal setting which was linked to the online log-books, provision of automated personalised feedback to participants, theoretical framework, the automated nature of the website and the ability for this website to effectively translate into real-life settings. Future research should continue to consider and identify ways to sustain and support long-term changes in physical activity, such as including ongoing web-based support.

In line with previous literature, intervention participants found the web-based programme useful and usable (Irvine et al., 2013; Leslie et al., 2005; McKay et al., 2001; Van den Berg et al., 2007). Specifically, the most favourably rated website components were the logbooks and education modules, which is consistent with the website usage data for those components. Another interesting finding relates to the use of the discussion forum. Although the discussion forum was the least favourably rated component of the website and only $26 \%$ of the participants actively posted on the discussion forum, there were 2961 views over the duration of the intervention. Previous research has found similar results with lower satisfaction and usage of discussion forums on physical activity websites (McKay et al., 2001; Van den Berg et al., 2007). However, the satisfaction results are in contrast to the high number of views. This could indicate that participants may have been 'lurking' rather than actively engaging in the use of the discussion forum. Alternatively, it could be that the small percentage of participants that were actively posting on the discussion forum were also responsible for the large number of forum views. Overall, usage of the web-based programme was positive, the average number of logins for intervention group participants was high, with an average of 21 (SD 33.65 ) for the duration of the 12 -week intervention. This equates to around 1.75 logins per person per week, which is similar to previous findings in individuals with Type 2 diabetes (McKay et al., 2001) and the general population (Steele et al., 2007c).

The large drop-out observed in the current study is cause for concern, and is a common issue among web-based programmes (Carr et al., 2008; Connelly et al., 2013; Kuijpers et al., 2013; Leslie et al., 2005; McConnon et al., 2007). Attrition at 12 weeks was $28 \%$ in the control group in comparison to $39 \%$ in the intervention group. This is greater than the average attrition of $27 \%$ observed in previous studies, although still not as high as some that reported up to $70 \%$ of the participants dropping out of the study before the post measure could be obtained (Vandelanotte et al., 2007). Although, participants that completed the intervention reported high website satisfaction, higher attrition was observed in the intervention group. Due to the nature of attrition, website satisfaction was not able to be collected for intervention participants who did not complete the 12 -week questionnaire. It could be that expectations were not being met for participants who dropped out of the study. Additionally, previous research has suggested that it is easier for participants to disengage with web-based programmes (Tate and Zabinski, 2003). It is clear however, that strategies for preventing attrition need to be investigated and implemented in web-based programmes.

It was interesting to observe the interaction effect for reduced weekday sitting time for the intervention group in the completer's analysis. Although sitting time was not specifically targeted throughout the intervention materials, the intervention group may have reduced their sitting time as a result of their increase in physical activity. This finding is important for people with Type 2 diabetes, as a reduction in sitting behaviour offers a number of health benefits independent of physical activity especially in relation to metabolic risk factors related to diabetes (Katzmarzyk et al., 2009). Previous research has shown that independent of physical activity, high sedentary time is associated with a detrimental effect on waist circumference, triglycerides, fasting plasma glucose (Healy et al., 2007, 2008) and insulin (Ekelund et al., 2007). Future interventions should also focus on reducing sitting time or sedentary behaviour in addition to increasing physical activity levels to elicit maximum health benefits.

\section{Limitations}

This study is not without limitations. Firstly, physical activity was measured by self-report methods, which are subject to over reporting. Although objective measures of physical activity are preferred, given the geographic divide of participants in this web-based intervention, and budgetary constraints, objective measurement of physical activity was not feasible. As such the IPAQ was chosen as the measure for physical activity, although the IPAQ was not developed for intervention research, it had been demonstrated to be an effective measure in previous web-based interventions and offered advantages in terms of assessing physical activity across multiple domains. It is possible that although the IPAQ has demonstrated a moderate correlation, which is comparable to other self-report questionnaires (Craig et al., 2003), it may lack the strength to detect longterm changes in physical activity. It is also possible that participants may have over-reported activity levels, which has been demonstrated in previous research (Johnson-Kozlow et al., 2006). Additionally, the use of pedometers, high attrition levels, and lack of the ability to measure decline in website usage are also limitations. The high attrition levels limit the generalisability of the findings and the results of the completers' analysis should be interpreted with caution. The study also contained significant strengths, which consisted of the use of a theoretical framework for intervention development and interactive website design.

\section{Conclusions}

These results provide some support for web-based programmes designed for individuals diagnosed with Type 2 diabetes to produce positive changes in short-term physical activity. However, maintaining these changes in physical activity remains challenging. Future research should consider developing programmes that offer ongoing web-based support that can continue to fully harness the reach and potential of web-based interventions. As Type 2 diabetes management is related to multiple health behaviours, future research should investigate if the same increase in physical activity behaviour can be obtained from interventions simultaneously targeting multiple behaviours, such as improving glucose control and diet, in the Type 2 diabetes population.

\section{Conflict of interest statement}

The authors declare that there are no conflicts of interest.

\section{Acknowledgments}

C.D. had full access to all of the data in the study and takes responsibility for the integrity of the data and the accuracy of the data analysis. All authors contributed to the drafting of the manuscript and critical revisions.

C.V. was supported by the National Health and Medical Research Council of Australia (\#519778) and the National Heart Foundation of Australia (\#PH 07B 3303) post-doctoral research fellowship. The other authors report no financial disclosures.

\section{Appendix A. Supplementary data}

Supplementary data to this article can be found online at http://dx. doi.org/10.1016/j.ypmed.2013.12.011. 


\section{References}

Ajzen, I., 1991. The theory of planned behavior. Organ. Behav. Hum. Decis. Process. 50, $179-211$.

American Diabetes Association, 2006. Standards of medical care in diabetes, 2006. Diabetes Care 29, S4-S42.

Armstrong, N., Powell, J., 2008. Preliminary test of an internet-based diabetes selfmanagement tool. J. Telemed. Telecare 14, 114.

Armstrong, N., Powell, J., Hearnshaw, H., Dale, J., 2007. Design of a trial of internet-based self-management for diabetes. J. Telemed. Telecare 13, 1-2.

Australian Bureau of Statistics, 2006. 2004-05 National Health Survey: Users' Guide (Canberra).

Australian Institute of Health and Welfare, 2008. Diabetes: Australian Facts 2008, Diabetes. AlHW, Canberra.

Bauman, A., Sallis, J.F., Dzewaltowski, D.A., Owen, N., 2002. Toward a better understanding of the influences on physical activity: the role of determinants, correlates, causal variables, mediators, moderators, and confounders. Am. J. Prev. Med. 23, 5-14.

Blanchard, C., Courneya, K.S., Rodgers, W., Murnaghan, D., 2002. Determinants of exercise intention and behavior in survivors of breast and prostate cancer: an application of the theory of planned behavior. Cancer Nurs. 25, 88-95.

Brug, J., Campbell, M., van Assema, P., 1999. The application and impact of computergenerated personalized nutrition education: a review of the literature. Patient Educ. Couns. 36, 145-156.

Carr, L.J., Bartee, R.T., Dorozynski, C., Broomfield, J.F., Smith, M.L., Smith, D.T., 2008. Internet-delivered behavior change program increases physical activity and improves cardiometabolic disease risk factors in sedentary adults: results of a randomized controlled trial. Prev. Med. 46, 431-438.

Carr, L.J., Dunsiger, S.I., Lewis, B., et al., 2013. Randomized controlled trial testing an internet physical activity intervention for sedentary adults. Health Psychol. 32, 328.

Cohen, J., 1992. A power primer. Psychol. Bull. 112, 155-159.

Conn, V.S., Hafdahl, A.R., Mehr, D.R., 2011. Interventions to increase physical activity among healthy adults: meta-analysis of outcomes. Am. J. Public Health 101, 751-758.

Connelly, J., Kirk, A., Masthoff, J., MacRury, S., 2013. The use of technology to promote physical activity in Type 2 diabetes management: a systematic review. Diabet. Med. 30, 1420-1432.

Courneya, K.S., Friedenreich, C., 1999. Utility of the theory of planned behavior for understanding exercise during breast cancer treatment. Psychooncology 8, 112-122.

Craig, C.L., Marshall, A., Sjöström, M., et al., 2003. International Physical Activity Questionnaire: 12-country reliability and validity. Med. Sci. Sports Exerc. 35, 1381-1395.

Crouter, S.E., Schneider, P.L., Karabulut, M., Bassett Jr., D.R., 2003. Validity of 10 electronic pedometers for measuring steps, distance, and energy cost. Med. Sci. Sports Exerc. 35, 1455.

Davies, C., Mummery, K., Steele, R., 2010. The relationship between personality, theory of planned behaviour and physical activity in individuals with Type II diabetes. Br. J. Sports Med. 44, 979-984.

Davies, C.A., Spence, J.C., Vandelanotte, C., Caperchione, C.M., Mummery, W.K., 2012. Meta-analysis of internet-delivered interventions to increase physical activity levels. Int. J. Behav. Nutr. Phys. Act. 9.

Ekelund, U., Griffin, S.J., Wareham, N.J., 2007. Physical activity and metabolic risk in individuals with a family history of Type 2 diabetes. Diabetes Care 30, 337-342.

Eysenbach, G., 2005. The law of attrition. J. Med. Internet Res. 7.

Glasgow, R.E., Boles, S.M., McKay, H.G., Feil, E.G., Barrera, M., 2003. The D-Net diabetes self-management program: long-term implementation, outcomes, and generalization results. Prev. Med. 36, 410-419.

Glasgow, R.E., Kurz, D., King, D., et al., 2010. Outcomes of minimal and moderate support versions of an internet-based diabetes self-management support program. J. Gen. Intern. Med. 1-8.

Glasgow, R.E., Kurz, D., King, D., et al., 2012. Twelve-month outcomes of an internet-based diabetes self-management support program. Patient Educ. Couns. 87, 81-92.

Hagger, M.S., Chatzisarantis, N.L.D., Biddle, S.J.H., 2002. A meta-analytic review of the theories of reasoned action and planned behavior in physical activity: predictive validity and the contribution of additional variables. J. Sport Exerc. Psychol. 24, 1-12.

Hays, L.M., Clark, D., 1999. Correlates of physical activity in a sample of older adults with Type 2 diabetes. Diabetes Care 22, 706

Healy, G.N., Dunstan, D.W., Salmon, J., et al., 2007. Objectively measured light-intensity physical activity is independently associated with 2-h plasma glucose. Diabetes Care 30, 1384-1389.

Healy, G., Wijndaele, K., Dunstan, D.W., et al., 2008. Objectively measured sedentary time, physical activity, and metabolic risk: the Australian diabetes, obesity and lifestyle study (AusDiab). Diabetes Care 31, 369.

Irvine, A.B., Gelatt, V.A., Seeley, J.R., Macfarlane, P., Gau, J.M., 2013. Web-based intervention to promote physical activity by sedentary older adults: randomized controlled trial. J. Med. Internet Res. 15.

Johnson-Kozlow, M., Sallis, J.F., Gilpin, E.A., Rock, C.L., Pierce, J.P., 2006. Comparative validation of the IPAQ and the 7-Day PAR among women diagnosed with breast cancer. Int. J. Behav. Nutr. Phys. Act. 3, 7.

Jones, L., Guill, B., Keir, S., et al., 2007. Using the theory of planned behavior to understand the determinants of exercise intention in patients diagnosed with primary brain cancer. Psychooncology 16, 232-240.

Katzmarzyk, P., Church, T., Craig, C.L., Bouchard, C., 2009. Sitting time and mortality from all causes, cardiovascular disease, and cancer. Med. Sci. Sports Exerc. 41, 998.

Kim, C.-J., Kang, D.-H., 2006. Utility of a web-based intervention for individuals with Type 2 diabetes. Comput. Inform. Nurs. 24, 337-345.
Kosma, M., Cardinal, B., McCubbin, J., 2005. Longitudinal effects of a web-based physica activity motivational program among adults with physical disabilities. Res. Q. Exerc. Sport 76, A116.

Kuijpers, W., Groen, W.G., Aaronson, N.K., van Harten, W.H., 2013. A systematic review of web-based interventions for patient empowerment and physical activity in chronic diseases: relevance for cancer survivors. J. Med. Internet Res. 15.

Leslie, E., Marshall, A., Owen, N., Bauman, A., 2005. Engagement and retention of participants in a physical activity website. Prev. Med. 40, 54-59.

Liebreich, T., Plotnikoff, R., Courneya, K., Boule, N., 2009. Diabetes NetPLAY: a physical activity website and linked email counselling randomized intervention for individuals with Type 2 diabetes. Int. J. Behav. Nutr. Phys. Act. 6, 18.

Lorig, K., Ritter, P.L., Laurent, D.D., et al., 2010. Online diabetes self-management program: a randomized study. Diabetes Care 33, 1275-1281.

Marshall, A., Owen, N., Bauman, A.E., 2004. Mediated approaches for influencing physical activity: update of the evidence on mass media, print, telephone and website delivery of interventions. J. Sci. Med. Sport 7, 74-80.

McConnon, A., Kirk, S.F., Cockroft, J.E., et al., 2007. The internet for weight control in an obese sample: results of a randomised controlled trial. BMC Health Serv. Res. 7, 206.

McKay, H.G., King, D., Eakin, E.G., Seeley, J.R., Glasgow, R.E., 2001. The diabetes network internet-based physical activity intervention: a randomized pilot study. Diabetes Care 24, 1328-1334.

McKay, H.G., Glasgow, R.E., Feil, E.G., Boles, S.M., Barrera, M., 2002. Internet-based diabetes self-management and support: initial outcomes from the diabetes network project. Rehabil. Psychol. 47, 31-48.

Morrato, E., Hill, J., Wyatt, H., Ghushchyan, V., Sullivan, P., 2007. Physical activity in U.S. adults with diabetes and at risk for developing diabetes, 2003. Diabetes Care 30, 203.

Nes, A.A.G., van Dulmen, S., Eide, E., et al., 2012. The development and feasibility of a webbased intervention with diaries and situational feedback via smartphone to support self-management in patients with diabetes Type 2. Diabetes Res. Clin. Pract. 97, 385-393.

Norman, G.J., Zabinski, M.F., Adams, M.A., Rosenberg, D.E., Yaroch, A.L., Atienza, A.A., 2007 A review of eHealth interventions for physical activity and dietary behavior change Am. J. Prev. Med. 33, 336-345 (e16).

Richardson, C.R., Mehari, K.S., McIntyre, L.G., et al., 2007. A randomized trial comparing structured and lifestyle goals in an internet-mediated walking program for people with Type 2 diabetes. Int. J. Behav. Nutr. Phys. Act. 4, 1-11.

Rooney, B., Smalley, K., Larson, J., Havens, S., 2003. Is knowing enough? Increasing physical activity by wearing a pedometer. Wis. Med. J. 102, 31-36.

Rotondi, A.J., Sinkule, J., Spring, M., 2005. An interactive web-based intervention for persons with TBI and their families: use and evaluation by female significant others. J. Head Trauma Rehabil. 20, 173-185.

Schneider, P.L., Crouter, S.E., Lukajic, O., Bassett Jr., D.R., 2003. Accuracy and reliability of 10 pedometers for measuring steps over a 400-m walk. Med. Sci. Sports Exerc. 35, 1779 .

Sigal, R.J., Kenny, G.P., Wasserman, D.H., Castaneda-Sceppa, C., White, R.D., 2006. Physical activity/exercise and Type 2 diabetes: a consensus statement from the American Diabetes Association. Diabetes Care 29, 1433-1438.

Spittaels, H., De Bourdeaudhuij, I., Brug, J., Vandelanotte, C., 2007a. Effectiveness of an online computer-tailored physical activity intervention in a real-life setting. Health Educ. Res. 22, 385-396.

Spittaels, H., De Bourdeaudhuij, I., Vandelanotte, C., 2007b. Evaluation of a websitedelivered computer-tailored intervention for increasing physical activity in the general population. Prev. Med. 44, 209-217.

Steele, R., Mummery, K., Dwyer, T., 2007a. Development and process evaluation of an internet-based physical activity behaviour change program. Patient Educ. Couns. 67 $127-136$.

Steele, R., Mummery, K., Dwyer, T., 2007b. Examination of program exposure across intervention delivery modes: face-to-face versus internet. Int. J. Behav. Nutr. Phys. Act. 4, 1-10.

Steele, R., Mummery, K., Dwyer, T., 2007c. Using the internet to promote physical activity: a randomized trial of intervention delivery modes. J. Phys. Act. Health 4, 245-260

Tate, D.F., Zabinski, M.F., 2003. Computer and internet applications for psychological treatment: update for clinicians. J. Clin. Psychol. 60, 209-220.

Thomas, S., Reading, J., Shephard, R., 1992. Revision of the physical activity readiness questionnaire (PAR-Q). Can. J. Sport Sci. 17, 338-345

Vallance, J.K.H., Courneya, K.S., Plotnikoff, R., Mackey, J.R., 2008. Analyzing theoretical mechanisms of physical activity behavior change in breast cancer survivors: results from the activity promotion (ACTION) trial. Ann. Behav. Med. 35, 150-158.

Van den Berg, M.H., Ronday, H.K., Peeters, A.J., et al., 2007. Engagement and satisfaction with an internet-based physical activity intervention in patients with rheumatoid arthritis. Rheumatology 46, 545-552.

Vandelanotte, C., Spathonis, K.M., Eakin, E.G., Owen, N., 2007. Website-delivered physical activity interventions: a review of the literature. Am. J. Prev. Med. 33, 54-64.

Winett, R.A., Anderson, E.S., Wojcik, J.R., Winett, S.G., Bowden, T., 2007. Guide to health: nutrition and physical activity outcomes of a group-randomized trial of an internetbased intervention in churches. Ann. Behav. Med. 33, 251-261.

World Health Organization, 1999. Definition, diagnosis and classification of diabetes mellitus and its complications. Part 1: Diagnosis and Classification of Diabetes Mellitus.Department of Noncommunicable Disease Surveillance, Geneva.

World Health Organization, 2004. Global Strategy on Diet and Physical Activity. 